\title{
Basics of recreation of ancient ceramics production technology
}

\author{
Elza Sutakova $^{1, *}$, and Alexei Mestnikov ${ }^{1}$ \\ ${ }^{1}$ M.K. Ammosov North-Eastern Federal University, 677000 Yakutsk, Russia
}

\begin{abstract}
The paper investigates possibility of ancient ceramics technology recreation based on materials of archaeological excavations and experimental simulation and describes results of the research. The structure and properties of ceramic samples found during archaeological excavations of the neolithic age and clay raw materials from different deposits were studied. The fragments under study were shown to consist mainly of lightmelting clays, possessing polimineral composition with additives of fire clay, sand, loose sedimentary rock, and in some cases wool and vegetation. Clays under study are characterized by variability of chemical and mineral composition, by their combining it is possible to obtain optimal moulding compositions to produce ceramic products of artistic and architecturalstructural purpose. Overview of scientific and technical information in archaeology and the obtained experimental results enable to reveal compositions and peculiarities of ancient technology of ceramics production and technical decoration application. Peculiar features of experimental simulation of the ancient ceramics technology considering chemical and mineral composition of clay raw materials are described.
\end{abstract}

\section{Introduction}

Ancient ceramics was initially used as houseware made from clay and it was the most popular and information-bearing material. For revealing the secrets of ancient ceramics technology latest results of archeological studies and analysis of existing materials may be useful [1].

It is known that talented craftsmen turn simple things into true pieces of applied arts. Ceramic art reached its highest development in Ancient Egypt, Assyria, Babylon, Greece, China and Hungary. Various museums of the world exhibit houseware made by ancient potters. The old masters were able to mould houseware of enormous sizes sometimes. Greek pithoi - vessels for water and wine which can be two meters high, strike by their highly technical implementation [2].

Ceramic pots and vessels in the Neolithic culture were made on a rather high technology level of that time. Items of different shape and size can be found, as different production techniques were used [3]. The round-bottomed ceramics of open-type with marked neck are generally met [4].

\footnotetext{
* Corresponding author: $\underline{\text { em.sut } @ \text { mail.ru }}$
} 
According to the existing archaeological remains and data of petrographic analysis moulding composition of ancient ceramics was defined [5]. The basic components of the composition were clay, sand of various fracture, rotted rock, wool, vegetation and fire clay. Ancient craftsmen used specially selected varieties of clay raw materials or mixtures on their basis for production of quality products [6]. Regulation of the ready products' properties was performed using additives of mineral and organic origin, as well as by applying different processing techniques [7].

From the viewpoint of construction engineering ceramic products attract by their durability, ease of manufacturing various products, availability of raw materials and low products cost, and possibility to organize small production. Therefore, studying ceramic fragments of ancient times is one of the most crucial and relevant objectives of ancient ceramics technology revival and its enhancement on a modern level. Revival of ancient ceramics production technology can be put into action in production of ceramic tiles and hardscape with decorative coating and exclusive painting which are of special demand for green construction [8-10].

Thus, experimental simulation of ancient technology requires conducting a complex of research of the existing samples of ancient ceramics and clay raw material for their production, as well as systematization and analysis of the obtained data. Defining the possibility for revival of ancient ceramics technology on the basis of archaeological excavations and experimental simulation using modern methods and facilities is the basic goal of the present study.

\section{Materials and methods}

The object of experimental study is samples of ancient ceramics and clay raw materials used for their production. The most difficult objective in experimental simulation of ancient ceramics technology is searching and obtaining permission for research of ceramic fragments being museum specimen. Moreover, the largest interest for research is ceramic samples of special purpose, e.g. large-size vessels with thin wall.

Ceramic fragment under study has waffle drawing performed on light-burning clay, peculiar for "Ymyyakhtatskaya culture" (archaelological culture of Siberia). "Ymyyakhtatskaya culture" is characterized by round-bottomed ceramics with the distinctive surface, waffle and ribbed imprint, dated II-I thd. B.C. [2].

Experimental simulation apart from ancient ceramic fragment was also applied to clay raw materials of different deposits of North Eastern Region of the Russian Federation.

Modern physical-chemical research methods enable to study structure and properties of materials, as well as define moulding composition of ancient ceramics and clay raw materials with high accuracy [11-12]. The studies were conducted with the help of X-ray spectral analysis using facility SRS-3400, X-ray powder diffraction apparatus ARL X TRA (Thermo Fisher Scientific, Switzerland), diffraction data bases ICDD PDF-2, search system Cristallografica Search - Match (Oxford Cryosystems), scanning electron microscope JEOL JSM-7800F.

\section{Results}

The sample of ceramic fragment under study contains aluminum oxides $-23.61 \mathrm{wt} . \%$, it is quite possible that it contains kaolinite minerals. Chemical analysis makes possible to confirm that ceramics under study was made from semi-acid clay with average grade of water-soluble salts. Considering ferrous oxide content it refers to clays with low content of 
colouring oxides. Apart from oxides given in Table 1, the following ones were also observed: $\mathrm{V}_{2} \mathrm{O}_{5}, \mathrm{Cr}_{2} \mathrm{O}_{3}$ and $\mathrm{MnO}$ in the amount of 0.01-0.02 wt.\%.

Table 1. Results of chemical analysis of ceramic fragment, wt.\%.

\begin{tabular}{ccccccccccc}
\hline $\mathrm{Na}_{2} \mathrm{O}$ & $\mathrm{MgO}$ & $\mathrm{Al}_{2} \mathrm{O}_{3}$ & $\mathrm{SiO}_{2}$ & $\mathbf{P}_{2} \mathbf{O}_{\mathbf{5}}$ & $\mathbf{S O}_{3}$ & $\mathrm{Cl}$ & $\mathbf{K}_{2} \mathrm{O}$ & $\mathbf{C a O}$ & $\mathbf{T i O}_{2}$ & $\mathbf{F e}_{2} \mathbf{O}_{3}$ \\
\hline 1.41 & 1.45 & 23.61 & 67.43 & 0.99 & 0.12 & 0.04 & 0.66 & 1.04 & 0.67 & 2.39 \\
\hline
\end{tabular}

$\mathrm{X}$-ray phase analysis identified variety of quartz, ferric hydroxysulfate, clinochrysotile, kaolinite, and muscovite in the ceramic sample under study. Diffraction angles of quartz, clinochrysotile, and kaolinite are quite well observed (Fig. 1). Clinochrysotile refers to the group of zeolite minerals.

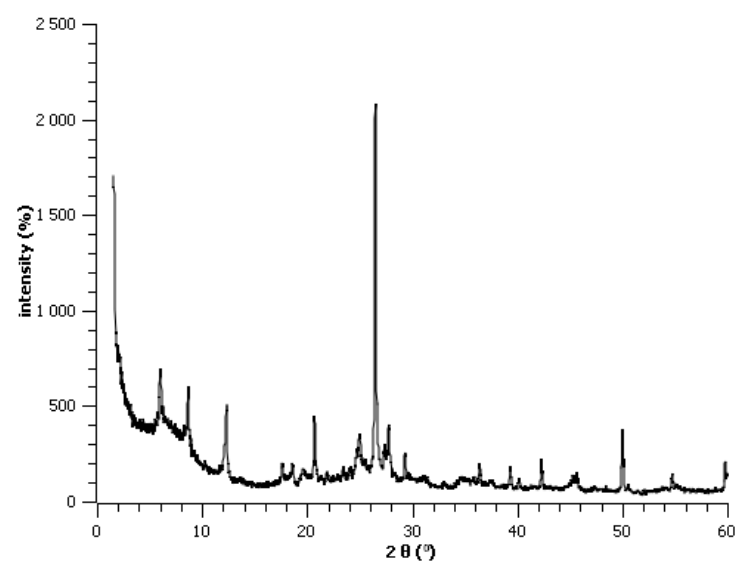

Fig. 1. X-ray pattern of the ceramic fragment.

Cross-sectional view of the ceramic fragment shows inhomogeneous composition, large size particles are visible, i.e. sand, possibly with fire clay additives. The arrangement of structure is close-packed; firing was probably conducted at the temperature close to $900^{\circ} \mathrm{C}$ (Fig. 2).

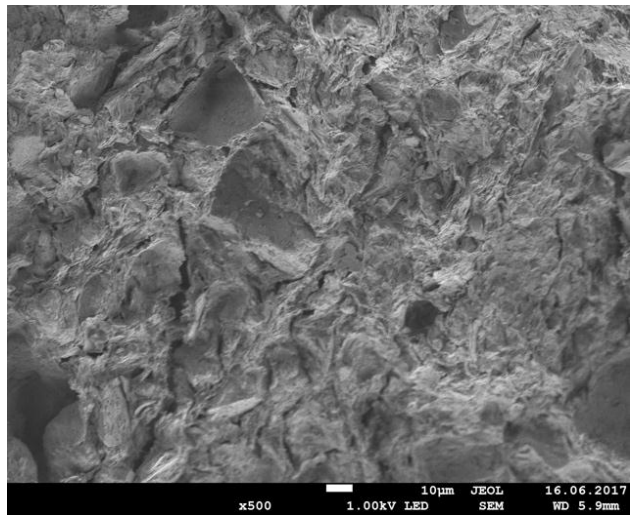

(a)

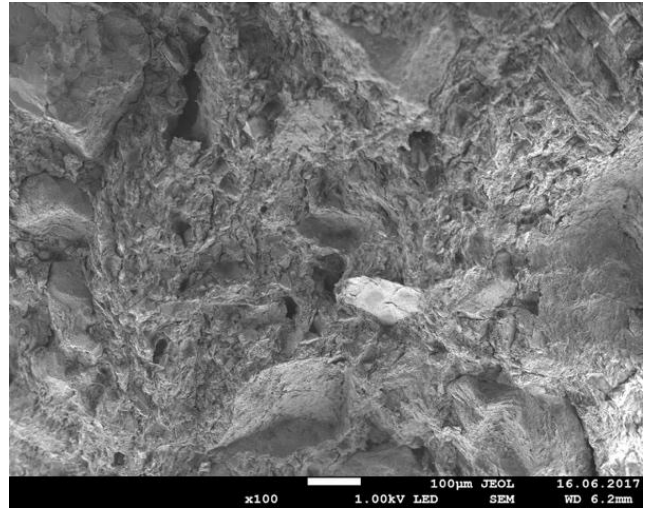

(b)

Fig. 2. Microstructure of ceramic fragment: $a$ - surface; $b$ - chip. 
Chemical composition was investigated (Table 2) along with mineral composition of the clay raw material from the four deposits of North Eastern region of the Russian Federation (Kangalasskoe 1, Kempendyaiskoe 2, Namtsyrskoe 3, Sannikovskoe 4).

Table 2. Chemical composition of the clay raw material, wt.\%.

\begin{tabular}{cccccccccc}
\hline $\mathbf{N o}$ & $\mathbf{S i O}_{2}$ & $\mathbf{A I}_{\mathbf{2}} \mathbf{O}_{\mathbf{3}}$ & $\mathbf{F e}_{\mathbf{2}} \mathbf{O}_{\mathbf{3}}$ & $\mathbf{C a O}$ & $\mathbf{M g O}$ & $\mathbf{P}_{\mathbf{2}} \mathbf{O}_{\mathbf{5}}$ & $\mathbf{K}_{\mathbf{2}} \mathbf{O}$ & $\mathbf{T i O}_{\mathbf{2}}$ & $\mathbf{N a}_{\mathbf{2}} \mathbf{O}$ \\
\hline 1 & 60.28 & 34.38 & 0.95 & 0.69 & 0.49 & 0.07 & 0.78 & 1.49 & 0.33 \\
\hline 2 & 42.62 & 11.22 & 5.68 & 16.69 & 14.41 & 0.19 & 4.31 & 0.83 & 2.77 \\
\hline 3 & 63.57 & 22.38 & 1.71 & 0.54 & 0.55 & 0.04 & 2.49 & 0.81 & 0.95 \\
\hline 4 & 61.44 & 14.23 & 14.39 & 4.28 & 2.14 & 0.13 & 2.63 & 0.73 & 2.11 \\
\hline
\end{tabular}

The clays of Namtsyrskoe deposit possess complex polimineral composition, minerals of quartz subgroup were revealed (quartz 56.5\%), potassium sodium feldspar (white feldspar $-11.5 \%$, orthoclase feldspar $-12.6 \%)$, kaolinite $(4 \%)$, as well as hydromicaceous minerals were observed $-4.9 \%$. Considering refractory properties the samples refer to lowmelting clays of polymineral composition, considering $\mathrm{Al}_{2} \mathrm{O}_{3}$ content they refer to semiacid clays, depending on the content of coloring oxides they refer to the group of average content of $\mathrm{Fe}_{2} \mathrm{O}_{3}$ and $\mathrm{TiO}_{2}$, and is characterized by the average content of water-soluble salts.

Sannikovskoe deposit contains the following minerals, wt.\%: quartz - 17.1; potash feldspar -24.4 ; muscovite -57.5 ; vermiculite -10.3 and cronstedtite -1.3 (Fig. 3 ). The revealed minerals refer to lamellar hydrosilicates. The deposit was defined as belonging to the group of moderate plastic, coarsely dispersed semi-acid clay raw with high content of silty particles, coloring oxides and soluble salts.

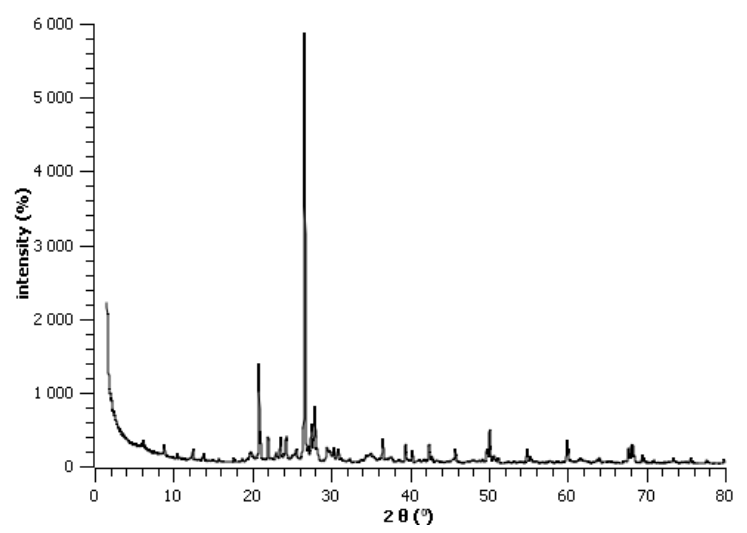

Fig. 3. X-ray pattern of clay raw from Sannikovskoe deposit.

Kempendyaiskoe deposit is characterized by high content of water-soluble salts. According to chemical composition it is characterized by low content of aluminum oxides $11.22 \%$, silicon oxides content is $42.62 \%$, considering content of coloring oxides it refers to clays with high content of: ferrous oxides $(5.68 \%)$, titanium oxide $(0.83 \%)$. With regard to mineral composition it is characterized by quartz content $(16.4 \%)$, muscovite $(41.4 \%)$, calc spar $(25.9 \%)$, dolomite $(13.7 \%)$, traces of hematite are observed $(2.6 \%)$.

Authors consider that the largest interest for manufacture of ceramic products of architectural construction and artistic purpose is presented by clay raw materials from Kangalasskoe deposit (Fig. 4). Clays are characterized by not high content of $\mathrm{Al}_{2} \mathrm{O}_{3}$ (34.38 wt.\%), low content of coloring oxides $\mathrm{Fe}_{2} \mathrm{O}_{3}-0.954, \mathrm{TiO}_{2}-1.49 \%$. The basic 
minerals are presented by kaolinite $-\mathrm{Al}_{4}\left[\mathrm{Si}_{4} \mathrm{O}_{10}\right](\mathrm{OH})_{8} \cdot \mathrm{nH}_{2} \mathrm{O}(69.8 \%)$, quartz $\mathrm{SiO}_{2}$ $(19.7 \%)$, according to $\mathrm{X}$-ray phase analysis presence of halloysite $\mathrm{Al}_{2} \mathrm{Si}_{2} \mathrm{O}_{5}(\mathrm{OH})_{4}(10.5 \%)$ is observed. Clay mineral of lamellar silicates subclass is close in its composition to kaolinite and refers to light-burning clays.

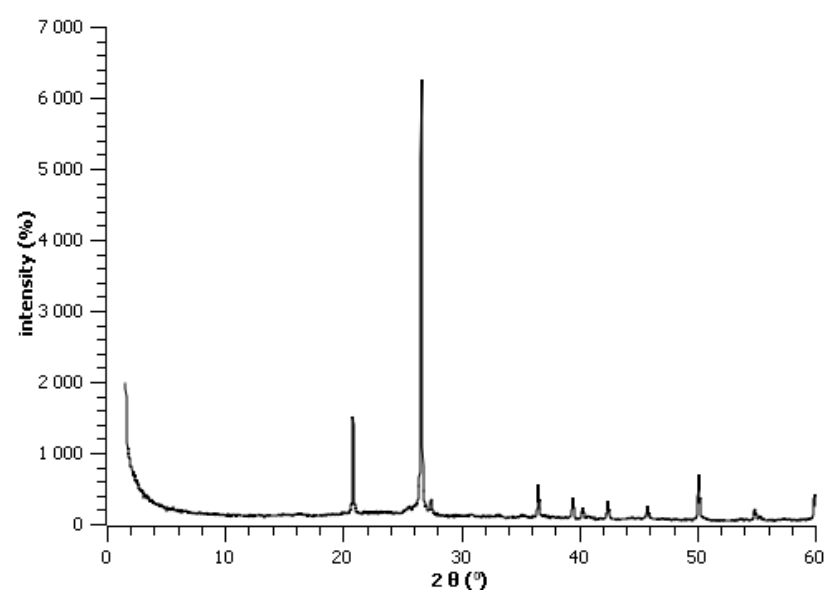

Fig. 4. X-ray pattern of clay raw material from Kangalasskoe deposit.

\section{Conclusions}

Overview of the literature data and results of experimental studies enable to make the following conclusions:

1) ancient masters used the simplest moulding composition for making household items, i.e. "clay + mineral additives (sand, rock pieces, fire clay) + organics (vegetation, wool)";

2) the basic secret of ancient technology lies in chemical-mineral composition of clay raw materials, thus proving comparison of experimental results of ancient ceramic fragment with clay samples from different deposits: for production of coarse ceramics (vessels of everyday use) ancient masters used the available kinds of clay, while for fine ceramics (regular and large-size vessels with thin walls) they looked for special kinds of clays that would satisfy the technology requirements.

Further research will be devoted to studying the ancient ceramics technology relating to large-size items production, recreation of their production technology and firing in nonindustrial conditions.

Authors acknowledge Ruslan A. Zakharov for providing materials for research, and Vasilii V. Mukhin, senior teacher of the Department of General, Analytical and Physical Chemistry, for valuable comments.

\section{References}

1. V.M. D'iakonov, Izvestija Laboratorii drevnih tehnologij [Reports of the Laboratory of ancient technologies], 1 (4), 104-119 ( 2006)

2. A. Cercone, M. Golitko, Poster at the SAA 81st Annual Meeting (Orlando, Florida, April 6-10, 2016)

3. S.A. Fedoseeva, Ymyjahtahskaja kul'tura Severo-Vostochnoj Azii [Ymyiakhtakh culture of Northeast Asia] (Nauka, Novosibirsk, 1980) 
4. V.M. D'iakonov, Drevnie kul'tury Mongolii i Bajkal'skoj Sibiri [Ancient cultures of Mongolia and Baikalian Siberia], Proceedings of the International Scientific Conference, 2, 163-170 (Irkutsk, Russia, May 3-7, 2011)

5. M. Romagnoli, American Ceramic Society Bulletin, 4, 9301-9304 (2005)

6. N.D. Yatsenko, É.O. Ratkova, Glass and Ceramics, 3, 93-94, (2009)

7. V.Z. Abdrakhimov, E.S. Abdrakhimova, News of higher educational institutions. Construction, 7, 12-16 (2006)

8. M. Golitko, European Journal of Archaeology, 14(3), 419-440 (2011)

9. H. Falih, Anbar Journal of Engineering Science, 3(2), 72-77 (2010)

10. T. Takeuchi, K. Nakamura, L.N. Mylnikova, S.P. Nesterov, N.A. Kulik, Ethnology and Anthropology of Eurasia, 37 (1), 39-51 (2009)

11. A. Mestnikov, S. Semenov, V. Strokova, V. Nelubova, AIP Conference Proceedings, 1698, 070010 (2016)

12. T.A. Khoroshun, I.M. Summamen, The role of natural science methods in archaeological research of ancient ceramics in Karelia. Institute of Language, Literature and History, Karelian Research Centre, Russian Academy of Sciences, 8, 17-27 (2015) 